\title{
Research and Practice of Higher Mathematics Teaching Reform under Application-oriented Talent Cultivation Mode
}

\author{
Tang Yugui \\ Nanchang Institute of Science and Technology, Nanchang, China
}

Keywords: applied; talent cultivation mode; higher mathematics; teaching reform

\begin{abstract}
In recent years, with the continuous development of social economy and improvement of scientific technology level, the requirements of talents' comprehensive quality and professional skills in the development of various industries are higher and higher. To satisfy the diversified requirement of talent from the development of society and industry, it is necessary to reform current educational mode. Colleges and universities can combine with students' and their actual situation and formulate targeted teaching plan. Especially for vocational colleges, applied talent is the important cultivation objective. Therefore, under the background of new era, colleges and universities shall continuously innovate teaching mode and thought, to train more practical talents for the society. In view of this, this paper mainly analyzes the reform and practice of higher mathematics teaching under the cultivation mode of applied talent.
\end{abstract}

In the education system of colleges and universities, higher mathematics is a vital part. However, based on the current status of actual education, it can be found that most teachers adopt traditional teaching mode and method and pay too much attention to students' understanding of relative data and improvement of calculation ability, thus ignoring the training of students' application ability, so that it is difficult for students to solve problems in daily life with the knowledge learned from classroom. In addition, higher mathematics is difficult with abstract and complex knowledge, and single teaching mode and method, which cannot mobilize students' learning enthusiasm and will reduce students' learning confidence. In order to solve this problem, teachers are required to actively transform teaching mode to better meet the requirement of social development, so that every student can become an excellent applied talent to contribute to industrial and social development.

\section{The Current Status of Higher Mathematics Teaching}

First of all, due to the difference of individuals, every student has his or her interest and personality characteristics, with different knowledge learning capability. Although many students sit in the classroom, they cannot put their concentration and mind in learning, resulting in the knowledge learning difference between different students. Besides, higher mathematics is boring and complex, requiring unified teaching. Even one part missing will affect follow-up learning. Because of students' different learning ability and quality, it is difficult for teachers to conduct the unified teaching and the quality of classroom teaching will be reduced. [1]

Secondly, with the rapid development of science and technology, the requirement of applied talents from all walks of life is higher, and the mastering of higher mathematics knowledge has gradually become the important standard for some industries to inspect talents. The traditional teaching mode of higher mathematics is mainly the teaching, the entire process is boring, which cannot inspire students' learning interest. Over time, students' learning attitude towards this discipline will change correspondingly, and even some students will give up halfway. To alleviate this problem, in future teaching practice, it is necessary for teachers to pay attention to the transformation of teaching method to increase vitality and vigor to the entire classroom teaching, and strengthen students' recognition and understanding of related knowledge so as to develop a correct and positive attitude towards the discipline.

Thirdly, the comprehensive competence of teachers is directly related to teaching quality and 
effects. Whereas, in current higher mathematics teaching practice, due to teachers' limited professional ability, they often cannot answer correctly students' questions in classroom, directly affecting students' learning motivation. The teaching mode is not novel, so in practice, teachers always adopt traditional teaching mode, basically transferring knowledge in textbooks to students simply. Over time, students depend more on teachers, even lacking the ability of independent thinking, which has direct impact on the improvement of students' independent learning ability. In view of this, teachers, in future teaching practice, shall continuously enhance their individual comprehensive competence and professional skills, innovate new teaching methods and thoughts and motivate students' learning interest.

\section{The Necessity of Higher Mathematics Teaching Reform under Applied Talent Cultivation Mode}

Based on current student enrollment of vocational colleges, first of all, the mathematics basis and understanding ability of relative mathematics knowledge of many students are different. Besides, there is great difference in students' learning attitude and interest. Therefore, all these factors will directly affect the teaching quality of higher mathematics. In order to alleviate this situation, it is necessary to conduct reform and innovation on current teaching mode. [2]

Then, for students who just enter colleges and universities, they have a vague understanding of higher mathematics, and insufficient recognition of its importance. Even some students think that higher mathematics has nothing to do with their own major, so it is not necessary to learn it deeply. This kind of thought results in problems such as students' ambiguous learning goal and insufficient learning motivation. For beginners of higher mathematics, this curriculum will increase incessantly in width and depth, with relatively abstract and complex knowledge, and there is higher requirement of students' logical thinking ability. Traditional teaching, if continues, will have an influence on students' learning quality and interest, so the teaching mode reform is needed.

Lastly, at present, many teachers of vocational colleges fail to establish a better cultivation awareness of applied talent. In teaching practice, they have unclear understanding of relative teaching objective and shallow research on professional knowledge. Some teachers just focus on the rigor, logic and theory of mathematics knowledge, ignoring the improvement of students' practical ability. In terms of teaching method, most teachers continue the spoon-feeding teaching and cramming teaching, paying attention to the explanation of mathematical formula. After a long time, students easily develop a formulated thinking and cannot think independently, which is not conductive to the improvement of their mathematical comprehensive ability. Therefore, the teaching mode reform is necessary. [3]

\section{Research and Practice of Higher Mathematics Teaching Reform under Applied Talent Cultivation Mode}

\subsection{The practice of level-based teaching mode}

The level-based teaching mode, based on the cultivation goal of applied talent, with improving students' mathematical comprehensive competence and ability of solving mathematical problems as the ultimate development goal, divides levels according to different situation of students, such as Class A and Class B. In general, Class A is students of mathematics major, and Class B can include non-mathematics students in computer, chemistry, physics, and economics, shown in Table 1 . Then, hierarchical teaching is conducted on different classes. For instance, if there are students with weak knowledge basis in Class A, they can be transferred to Class B. In addition, to enhance students' learning interest, teachers can implement rolling teaching mode according to students' willingness. For example, teachers can adjust class level based on students' grade after the final exam. For students with excellent performance in Class B, teachers can transfer them to Class A according to their willingness. [4] 
Table 1 Schedules and involved major of Class A and Class B

\begin{tabular}{|c|c|c|c|}
\hline Class & $\begin{array}{c}\text { Week class hour in } \\
\text { the first semester }\end{array}$ & $\begin{array}{c}\text { Week class hour in } \\
\text { the first semester }\end{array}$ & Involved major \\
\hline Class A & 6 & 6 & Mathematics \\
\hline Class B & 4 & 4 & $\begin{array}{c}\text { Computer, } \\
\text { chemistry, physics, } \\
\text { economics, etc. }\end{array}$ \\
\hline
\end{tabular}

For Class A students, the school can send teachers with practical experience and high professional quality to teach. In practice, the proportion of exercises can be increased appropriately. Through practice and explanation, students can have a basic comprehensive understanding of question type and content of higher mathematics, so as to enhance their learning experience and ability to take exams. In addition, students need to develop their hands-on practical ability to learn to use mathematical software to solve mathematical problems in scientific research and engineering. [5]

Students' performance can be obtained through examinations. And to set exam questions separately for two levels of classes to ensure the fairness and objectivity of the examination. For students in Class A, the proportion of basic questions can be increased appropriately, and the proportion of improvement questions can be reduced, and opposite question setting for Class B, shown in Table 2.

Table 2 The proportion of exam question type for Class A and Class B

\begin{tabular}{|c|c|c|c|}
\hline & Basic questions & Medium questions & $\begin{array}{c}\text { Improvement } \\
\text { questions }\end{array}$ \\
\hline Class A & $30 \%$ & $50 \%$ & $20 \%$ \\
\hline Class B & $50 \%$ & $45 \%$ & $5 \%$ \\
\hline
\end{tabular}

A certain college adopted this hierarchical teaching mode in the higher mathematics teaching, the teaching content including ordinary differential equations, probability statistics, linear algebra and so on. Practice shows that in the final exam, the pass rate of Class A and Class B students is as high as $88 \%$, which is much higher than $65 \%$ under the normal teaching mode. The comprehensive teaching effect is very significant. [6]

\subsection{To optimize the teaching mode and realize the close connection between theory and reality}

In high school mathematics textbooks, many mathematics problems comes from the reality of life. For this reason, in practical teaching, teachers can adjust the relevant teaching content according to the actual situation to enhance students' application ability, innovation ability and thinking quality.

For example, when teaching the relevant content of the "unary function value theorem", teachers can introduce relevant cases. For instance, Zhang first departure from A city at 8 o'clock on the first day, reach destination B city at 15 o'clock in the afternoon, departs from destination B city and returns to the departure place on the second day at 8 o'clock, and arrives at the A city at 15 o'clock. The question is whether there is such a point where the watch shows the same time in the two days when Zhang passes this point. In practice teaching, teachers can create problem situations for students in light of actual conditions, and at the same time establish corresponding mathematical models, enumerate known functions, such as, $\mathrm{f}(\mathrm{a})=8 \mathrm{f}(\mathrm{b})=15$ 、 $\mathrm{g}(\mathrm{b})=8$, to verify whether there is a point $x_{0} \in[a, b], \mathrm{g}\left(x_{0}\right)=f\left(x_{0}\right)$. Through the above questions, not only students can have a deep and detailed understanding of the relevant connotation of the "value theorem", but also students can apply the knowledge learned in the classroom to solve common problems in real life, and train and improve their knowledge application ability. [7] 


\subsection{To train students' awareness of mathematical modeling and improve their knowledge comprehensive application ability}

In practical teaching, it is necessary to train students' awareness of mathematical modeling. For example, in explaining the maximum and minimum and the extreme value of the function, combined with the knowledge of the maximum and minimum learned in the past, the following problems can generally be raised. In the process of making the covered container, the materials used are the least when the height and diameter are the same, but in real life, many common can designs are not the same. The height of most cans are longer than the diameter. Why? In practice, teachers can first provide some cans for students, and let students observe in the class. It is not difficult to find that the thickness of the upper and lower bottoms of the cans is greater than the thickness of the side walls. About the problem of the material used in container, the sidewall and the thickness of the upper and lower bottom will have an effect on the result. [8]

In the process of solving the problem, teachers can set the height of the can container to $h$, the radius of the bottom to $\mathrm{r}$, the volume to $\mathrm{A}$, and the thickness of the upper and lower bottom of the container to be $f$ times the thickness of the sidewall, thereby obtaining the equation.

$$
\mathrm{V}=2 p \pi r^{2}+2 \pi r h=2 p \pi \cdot \frac{A}{\pi r^{2}}=2 p \pi r^{2}+\frac{2 A}{r}(r>0) \text {. }
$$

When $\frac{\mathrm{d} V}{\mathrm{dr}}=4 p \pi r-\frac{2 \mathrm{~A}}{r}=0$, it can be obtained that there is the only stagnation point when $r=\left(\frac{A}{2 p \pi}\right)^{\frac{1}{2}}$, and $h=\frac{A}{\pi r^{2}}=p \cdot\left(\frac{A}{2 p \pi}\right)=p \cdot 2 r$.

Through the formula, students will understand why common cans are designed this way in daily life. After completing the teaching, teachers can perform group teaching, to measure the height, width, wall thickness and thickness of the upper and lower bottom of the cans, and at the same time, analyze and collect relevant data through network, and guide students to complete the design of cans in groups.

\subsection{To realize diversified teaching modes.}

In the teaching of higher mathematics, the teaching method adopted has a direct influence on students' learning motivation and effect. Traditional cramming teaching mode cannot mobilize students learning initiative, and this discipline is difficult, so students lose learning confidence easily. In view of this, teachers are required to actively innovate teaching thought and mode and continuously adopt diversified teaching modes to increase vigor and vitality to the classroom. [9]

In practical teaching, teachers are able to adopt corresponding teaching mode according to different teaching contents, train students' learning interest and inspire their learning enthusiasm. For instance, in teaching indefinite integral, derivative, definite integral and so on, teachers can teach in explaining; in teaching the application of integral and derivative, teachers can try to adopt self-learning and guidance method, and organize seminar regularly to provide the opportunity for students to teach on the stage. The difference of teaching object and teaching contents directly decides the diversity of teaching method, which is also the key to enhancing the teaching quality. In practical teaching, teachers shall fully respect the subject role of students, strengthen the interaction and communication between teachers and students, and conclude new teaching mode in practice.

In modern teaching of higher mathematics, mathematical software, electronic teaching plan, mathematical CAI and so on can be applied to focus on the teaching important points and essence, and highlight the teachers' function of teaching guidance, in the formula, graphics and numerical values of mathematical object. [10]

\section{Conclusion}

In summary, this paper mainly analyzes the current status of higher mathematics teaching and the 
necessity of its teaching reform under the cultivation mode of applied talent, and puts forward effective suggestions on the reform of teaching mode. In a word, with the continuous development of modern social economy, the application range of higher mathematics is wider, which puts forward higher requirement for talent cultivation. For vocational colleges, in order to train more excellent applied talents, it is necessary to conduct the reform on current teaching mode, adopt diversified teaching means according to students' actual situation, optimize teaching contents, enhance students' learning enthusiasm, put forward targeted solutions based on existing problems in current teaching mode, and formulate brand new teaching plan, so as to lay a solid foundation for improving the teaching quality of higher mathematics, and educate more applied talents in mathematics for the industrial and social development.

\section{Acknowledgements}

Fund Project: This work is the project of the $13^{\text {th }}$ "Five-Year" plan of Jiangxi provincial education and science plan. Project Name: Research on Chinese Learning Anxiety of Tibetan National Minority -Taking Nanchang Institute of Science and Technology as an Example. Project No. 17 YB253.

\section{References}

[1] Li Guanmin. 3. Research and Exploration of Higher Mathematics Curriculum Teaching Reform under the Cultivation Mode of Applied Talent [J]. Management \& Technology of SME (Late Issue), 2016(10):138-139.

[2] Xu Yingxiang, Wen Juan. Research on Mathematics Curriculum Teaching Reform under the Cultivation Mode of Applied Talent -Taking Yixian Class in Xinhua College of Sun Yat-sen University [J]. University Education, 2017(11):139-141.

[3] Wang Jing. Wei Jia. Exploration on Teaching Reform of Advanced Mathematics under Application-oriented Innovative Talents Cultivation Mode [J]. Journal of Gansu Lianhe University (Natural Sciences), 2013, 27(3):95-97.

[4] Yu Shuimeng. An Exploration \& Analysis on Teaching Reform of Advanced Mathematics under Application-oriented Innovative Talents Cultivation Mode [J]. Journal of Jiangnan University (Education Sciences), 2015(3):282-284.

[5] Yang Shijuan. Research on Teaching Reform of Higher Mathematics Curriculum in Local Application -oriented Undergraduate Colleges -Taking Huangshan University as an Example [J]. Science \& Technology Vision, 2017(2):557-574.

[6] Duan Yuan, Hu Guoyi. Research and Practice of Teaching Reform of Higher Mathematics Curriculum in Application-oriented Undergraduate Colleges -Taking Computer Major in Guangdong University of Science \& Technology [J]. New Curriculum Research (Mid-month Issue), 2017(6):154-516.

[7] Zhao Shuang, Zhang Yuyan, Zhang Hengyu. The Recognition and Practice of Teaching Interaction Structure Mode Based on Application-oriented Talent Cultivation [J]. Journal of Chifeng University (Natural Science Edition), 2015(17):234-235.

[8] Liu Chunjie. The Reform and Innovation of Higher Mathematics Curriculum Adapting to Higher Application-oriented Talent Cultivation [J]. Journal of Chifeng University (Natural Science Edition), 2013(3):265-278.

[9] Zheng Qingyun, Bai Jianxia. Let Every Student Shine -Research and Practice of Higher Mathematics Teaching Reform in Independent Colleges [J]. Course Education Research, 2013(24):759-651.

[10] Chen Xuemei. Research and practice on the teaching reform of advanced mathematics in the application of "student-centered"__ a case study of Harbin Guangsha University [J]. Heilongjiang Science, 2017, 8(11):724-723. 